\title{
Amphibian phylogeography: a model for understanding historical aspects of species distributions
}

\author{
I Zeisset and TJC Beebee \\ School of Life Sciences, University of Sussex, Falmer, Brighton, UK
}

\begin{abstract}
Phylogeographic analysis has become a major tool for investigating historical aspects of biogeography and population genetic structure. Anuran amphibians are particularly informative subjects for phylogeographic research on account of their global distribution, high degree of population genetic structure and ease of sampling. Studies on all the world's inhabited continents have demonstrated the nature and locations of refugia, including the Gulf Coast in North America and the Mediterranean peninsulas in Europe during the Pleistocene glaciations; the importance of vicariance events such as the uplift of the Andes in shaping modern distributions; and
\end{abstract}

Keywords: anuran; biogeography; population history

\section{Introduction}

Phylogeography, analysis of the relationship between population genetic structure and biogeography, has proved to be a powerful tool in the study of historical influences on animal and plant distributions since its inception some 20 years ago (Avise et al., 1987) and has been applied to a wide range of taxa in most parts of the world (Avise, 2000). A central objective of phylogeography is to explain patterns of population history across the globe, taking account of major regional differences in latitude, topography and ocean currents (Hewitt, 2000). Phylogeographic analysis is based on the comparison of genotype information, often derived from mitochondrial DNA (mtDNA) sequences, sampled from populations across a distribution range. The main analytical methods used in phylogeography are based on tree building and the derivation of mtDNA haplotype networks. The genetic data are then interpreted chronologically wherever possible, and superimposed on geography. The relationship of genotype and geographical distributions is then interpreted to infer population histories.

The timescale of major events within the last few million years, which includes the period over which many current distributions became established, is summarized in Figure 1. Substitution rates in mtDNA

Correspondence: Professor TJC Beebee, School of Life Sciences, University of Sussex, Falmer, Brighton BN1 9QG, UK.

E-mail: t.j.c.beebee@sussex.ac.uk

Received 14 November 2007; revised 4 February 2008; accepted 18 March 2008; published online 21 May 2008 colonization routes in temperate zones during postglacial climatic amelioration. Features identified as important to amphibian biogeography, notably mountain ranges, large rivers such as the Amazon and climatic fluctuations, are common to many other taxa. New analytical methods based on coalescent, Bayesian and likelihood approaches permit more rigorous hypothesis testing than has hitherto been possible and offer the prospect of even more detailed insights into species and population history in future work. Heredity (2008) 101, 109-119; doi:10.1038/hdy.2008.30; published online 21 May 2008 tend to plateau after 15-20 million years (MY), presumably as a result of variable site saturation. Microsatellites, also popular for reconstructions of population history, have a much more limited (and thus more recent) useful timeframe. Major factors thought to have influenced current biogeographical distributions over the late Miocene/Holocene timeframe include vicariance events such as mountain uplift, especially in the Neogene period, and the Pleistocene glaciation-interglacial cycles that began 1-2 MYBP (MY before present). These cycles continued until the most recent interglacial, which started 18-20000 YBP and gave rise to the Holocene epoch after a final, brief cold introgression around $11000 \mathrm{YBP}$.

In this review, we focus on examples from one particular group of animals, the anuran amphibians (frogs and toads). For assessing the value of phylogeographic studies, they have several advantages. Amphibians generally exhibit low individual mobility, often accompanied by high philopatry to natal sites (Beebee, 1996). Populations consequently tend to be highly structured genetically over short geographical distances, and retain high-resolution signals of historical events that generated current species distributions. In this respect, they differ significantly from more mobile species, extremes of which include birds and flying insects, and many plants that generate pollen or seeds that are regularly transported over long distances. Amphibians are also relatively easy to sample, more so for example than most small mammals or reptiles, which also have low mobilities and thus potentially strong phylogeographic signals. Finally, anuran amphibians 
have a worldwide distribution and substantial species diversity, on all continents except Antarctica (Duellman and Trueb, 1986).

Phylogeographic analysis of amphibian species from temperate and tropical regions therefore has the potential to provide powerful insights into late Tertiary and Quaternary Period influences on biogeographical processes. We consider these events in two rather different situations: the north temperate zone, directly affected by expanding ice sheets during the Pleistocene, and the tropical/south temperate zone where the consequences of glaciation were mostly indirect but just as significant. Finally, we consider how successful the methods of phylogeographic analysis have been at distinguishing between different hypotheses and likely future developments in this increasingly important research area.

\section{North temperate zone: North America and Europe}

Important features relevant to the phylogeography of North America are outlined in Figure 2. At the last glacial maximum, northern parts of the continent were

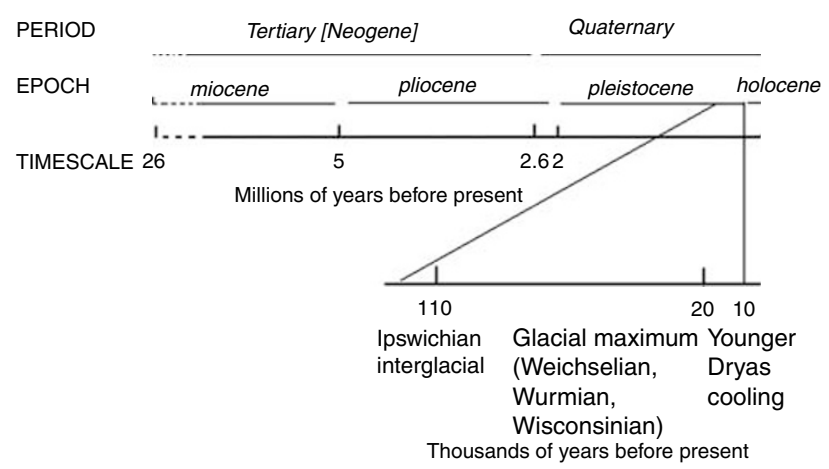

Figure 1 Historical periods most accessible to phylogeographic analysis. covered by extended polar ice sheets, and the major mountain ranges were glaciated. Climatic conditions at times during the Pleistocene were most severe in the mountainous west, and there is also evidence of extreme aridification in the west and north central USA around 14000 YBP (Starkey et al., 2003).

The species richness of many taxa in the south-eastern USA, in particular, indicates the presence of multiple refugia in this area during the Pleistocene (Hewitt, 2000). Many of the most widespread anurans in North America occur today between the east coast and the Rocky Mountains. Rana catesbeiana, the North American bullfrog, can be differentiated into two major genetic lineages using $c y t b$ mtDNA sequences (Austin et al., 2004). A monophyletic western group was derived from a more genetically diverse eastern group and the two were isolated allopatrically during the early Pleistocene by the Mississippi basin; both groups probably survived the glaciation in the coastal plains. The spring peeper Pseudacris crucifer is also allopatrically differentiated into eastern and western groups, but in this case with glacial refugia in multiple sites in the south Appalachians and in the Ozark central highlands, respectively (Austin et al., 2004). The depth of divergence in this species indicates late Pliocene vicariance as an early cause. Longitudinal genetic breaks occur for both species, corresponding to the Mississippi river and Appalachian mountains. $P$. crucifer differentiated into distinct eastern and central clades on either side of the Appalachians. Highest levels of genetic diversity for both species occur in Ontario, a region of admixture where previously separate lineages have made secondary (postglacial) contact (Austin et al., 2004). Geographical overlap of eastern and western clades today demonstrate that the Mississippi has not acted as a continuous barrier, particularly for $R$. catesbeiana, and was probably most effective during interglacial periods of high sea level. Nested clade analysis (NCA), a widely used method in phylogeography, inferred postglacial range expansions in both species. P. crucifer, for example, seems to have spread

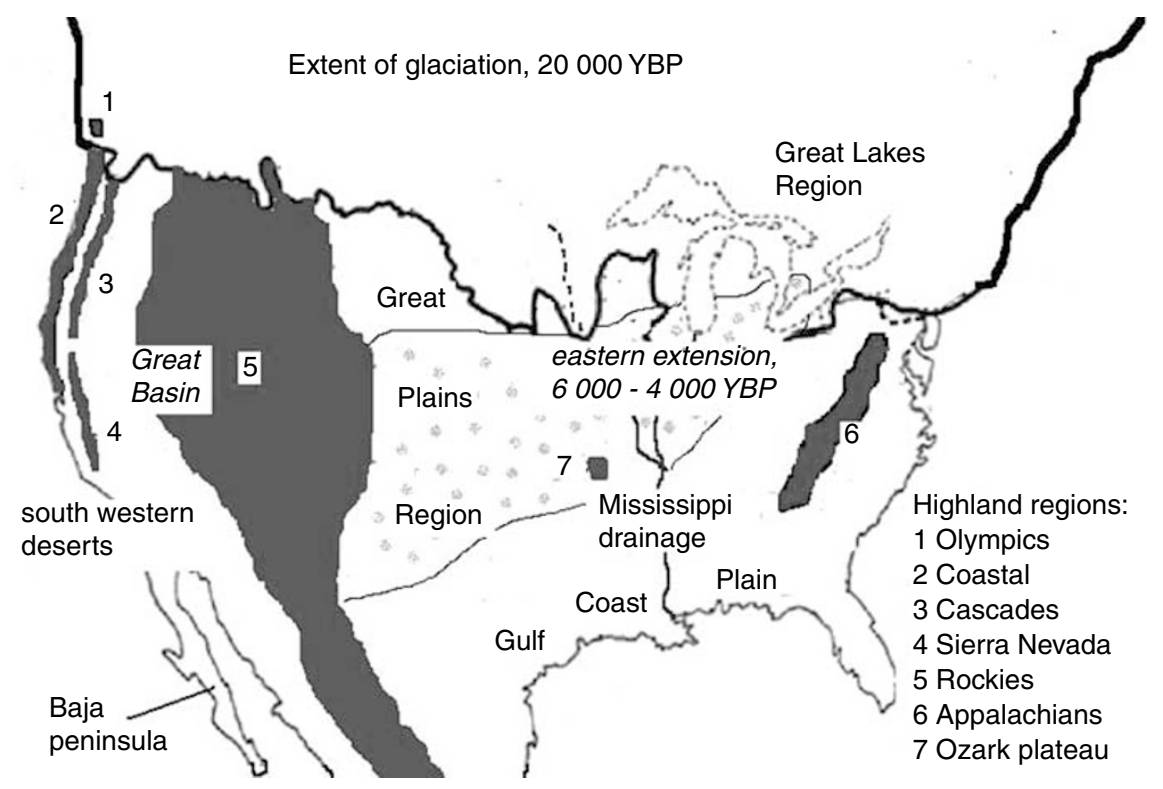

Figure 2 North American phylogeography; historical and physical features. 


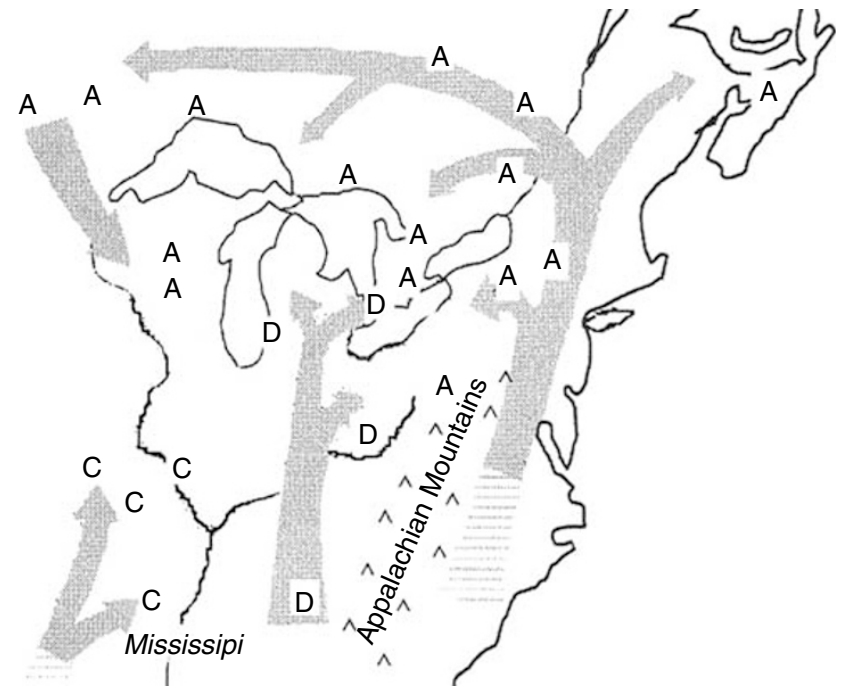

Figure 3 Proposed postglacial colonization patterns of Pseudacris crucifer clades in eastern North America (after (Austin et al., 2002). (A, C and D) Northern, Western and Central clades respectively.

north from both east and west of the Appalachians and then around the Great Lakes (Figure 3), generating admixture with each other (clades A and D) and with the advancing western clade C (Austin et al., 2002, 2004). NCA applies statistical tests to haplotype networks, followed by more subjective inferences about what the statistically robust patterns might mean. Unfortunately, there is evidence that NCA sometimes produces misleading results, and especially an excess of 'false positive' conclusions concerning restricted gene flow and contiguous range expansion (Petit, 2008). Conclusions based primarily on NCA should therefore be viewed with caution. A more wide-ranging study of all Pseudacris species identified four major clades on the basis of mt 12S and 16S ribosomal RNA genes (Moriarty and Cannatella, 2004) and confirmed the importance of the Mississippi as a barrier generating allopatric differentiation. As with $R$. catesbeiana, genetic diversity was much lower in the west than in the east.

Many similar features can be seen in another of North America's most widespread anurans in this region, the northern leopard frog $R$. pipiens (Hoffman and Blouin, 2004). Eastern and western clades, separated by the Mississippi, diverged at the end of the Pliocene. Current haplotype distributions are best explained by restricted gene flow with isolation by distance, which may be a characteristic feature of taxa (including amphibians) that have restricted individual mobility. Although eastern frog populations again have the highest levels of genetic diversity, with inference of multiple Pleistocene refugia, it seems probable that they were originally founded by a few migrants originating west of the Mississippi. Mismatch distribution analysis inferences for this species include evidence of both bottlenecks and major population expansions during the glacial/interglacial cycles some 300 000-500 000 YBP. Mismatch distribution analysis compares frequencies of numbers of mutational differences between haplotypes in a population with those expected by simulated models fitted to the data. Range expansion is inferred from smooth or unimodal distributions.
For many of these eastern species, Pleistocene refugia evidently occurred in the relatively mild Gulf coast plain and the Atlantic coast. Additionally, highland forest refugia in the Appalachians and the Ozark central plateau were probably important during the periods of high aridity (Starkey et al., 2003). Substantial barriers to gene flow have been the Mississippi (mainly effective during times of high sea levels), the mountain ranges and the uplifting of plateaux during the MiocenePliocene (Riddle and Hafner, 2006). Severe bottlenecks in western populations in this region, caused by the extreme climatic fluctuations prevailing there, are a likely cause of the low genetic diversity commonly observed in western clades. Allopatric breaks associated with the Mississippi basin, and postglacial expansions from Appalachian and coastal plain refugia, have been identified in many different vertebrates (Austin et al., 2004; Soltis et al., 2006).

In western North America, amphibians have also provided insights into historical events in arid and mountainous regions. The red-spotted toad Bufo punctatus inhabits warm and dry regions of the southwest. A $c y t b$-based study identified three main clades with little geographical overlap: eastern and western groups separated by the Rocky Mountains, and a third group in the Baja peninsula (Jaeger et al., 2005). Divergence of these clades was probably initiated during the period from late Miocene to the early Pliocene, by vicariance events including the uplifting of the Colorado and other plateaux near the continental divide. High genetic diversity in the far western region suggests that this was the most successful Pleistocene refuge, and NCA yielded signals of subsequent range expansion and population growth, particularly in the east, leading to some secondary contacts. The $c y t b$-inferred history of the Columbia spotted frog ( $R$. lutreventris), which ranges from the western USA to Alaska, also implicates Miocene events (uplift of the Utah-Nevada Great Basin, and cold, dry climate) as the primary structuring force separating clades of this mountain-dwelling species north of and around the Great Basin (Bos and Sites, 2001). The tailed frogs (Ascaphus truei and A. montanus), cold-tolerant inhabitants of mountain streams in the north-west, have received intensive phylogeographic study. Random amplified polymorphic DNA analyses identified three genetic groups of $A$. truei in Canada, two (north and south) in the Coastal range and one inland, with low genetic diversity, in the northern Cascades (Ritland et al., 2000). All these mountainous regions were ice covered 20000 YBP (Pielou, 1991). Later studies using mtDNA (cytb and ND2 sequences) indicated a late Miocene split between the coastal (A. truei) and inland Rocky Mountain (A. montanus) groups, perhaps mediated by rainshadow (aridification) effects of the rising Cascades on the intervening habitat (Nielson et al., 2001). Four coastal clades of $A$. truei and two inland clades of $A$. montanus probably diverged during the early Pleistocene, as a consequence of glaciation and summer drought-generated refugia (Nielson et al., 2001). Arid intervening habitat has persisted through the Holocene. The separation of Ascaphus into two species (truei and montanus) was confirmed by allozyme and further $c y t b$ analyses, which also indicated recent gene flow among Coastal range populations of $A$. truei and a discrete Olympic mountains clade of this species (Nielson et al., 2006). 
A combination of NCA, tree topologies, genotype assignments and an integrated coalescent and ecological niche model favoured dual Rocky Mountain (rather than a western) refugia for A. montanus (Carstens and Richards, 2007).

For the west-coast mountain red-legged frog complex, $c y t b$ studies demonstrated that two sister taxa ( $R$. aurora in the north and $R$. draytonii in the south) are distinct but do not constitute a monophyletic group. Their separation zone, just north of San Francisco Bay, constitutes a range border for many taxa including several other amphibians (Shaffer et al., 2004). Such latitudinal divides also occur elsewhere along the west coast mountains, for example, with the cascades frog $R$. cascadae, which is more closely related to $R$. aurora than is $R$. draytonii (Shaffer et al., 2004). R. cascadae also reaches its southern range limit in northern California, but is mainly confined to the more inland Cascades range with an outpost in the Olympic range. MtDNA (control region, ND1 and tRNA sequence) analysis demonstrated three main clades in the Olympic, Cascades and north California regions and indicated that the Olympic and Cascades populations have been separated for 2-3 million YBP (Monsen and Blouin, 2003). However, a comparative analysis with six microsatellite loci showed far less genetic differentiation and thus indicated a much more recent separation. One explanation for this apparent discrepancy is that following initial pre-Pleistocene separation there has been secondary contact sometime during the Holocene. The microsatellite data also indicated another divide among $R$. cascadae populations, this time within the Cascades across the Columbia River.

Over 150 invertebrates, bryophytes, lichens and vascular plants share similar distributions to Ascaphus in the Pacific northwest, and several urodele amphibians also have comparable phylogeographies (Nielson et al., 2001). Phylogenetic breaks identified with amphibians in
California have been found in plants, reptiles, birds and mammals (Shaffer et al., 2004). In general, the studies, rather remarkably, suggest the existence of Pleistocene refugia for many of the relatively cold-tolerant northwestern species in patches of forested river valleys within the otherwise very cold mountain zones.

Historical and geographical features relevant to the recent past in Europe are shown in Figure 4. It is well established that the three Mediterranean peninsulas (Iberia, Italy and the Balkans) as well as more easterly regions such as the Caucasus provided refugia for a wide range of animal and plant species throughout the Pleistocene. Early phylogeographical studies inferred that northerly expansions from these refugia during the late Pleistocene and early Holocene can explain the current distributions of a wide range of European taxa, including various suture zones where the colonists came into secondary contact (Taberlet et al., 1998; Hewitt, 1999, 2000, 2001). The south-eastern (Balkan) refuge area was the most successful provider of colonists, possibly because barriers to northerly migration in this region are less severe than the Pyrenees or Alps further west. Thus, Balkan populations of the spadefoot toad P. fuscus have the typically much higher genetic diversity found in long-standing refugia than do their conspecifics in northern Europe, which was probably colonized during or just after the Younger Dryas cold interval around 11000 YBP (Eggert et al., 2006).

It is increasingly clear, however, that some animals and plants survived the recent glacial maximum in more northerly 'cryptic' refugia as well as in the main areas of the Mediterranean peninsulas (Stewart and Lister, 2001). MtDNA studies show that the northern crested newt Triturus cristatus fits this pattern (Wallis and Arntzen, 1989; Eggert et al., 2006), as do the cold-tolerant moor frog $R$. arvalis and common frog $R$. temporaria. Both of these anurans currently range further north than the

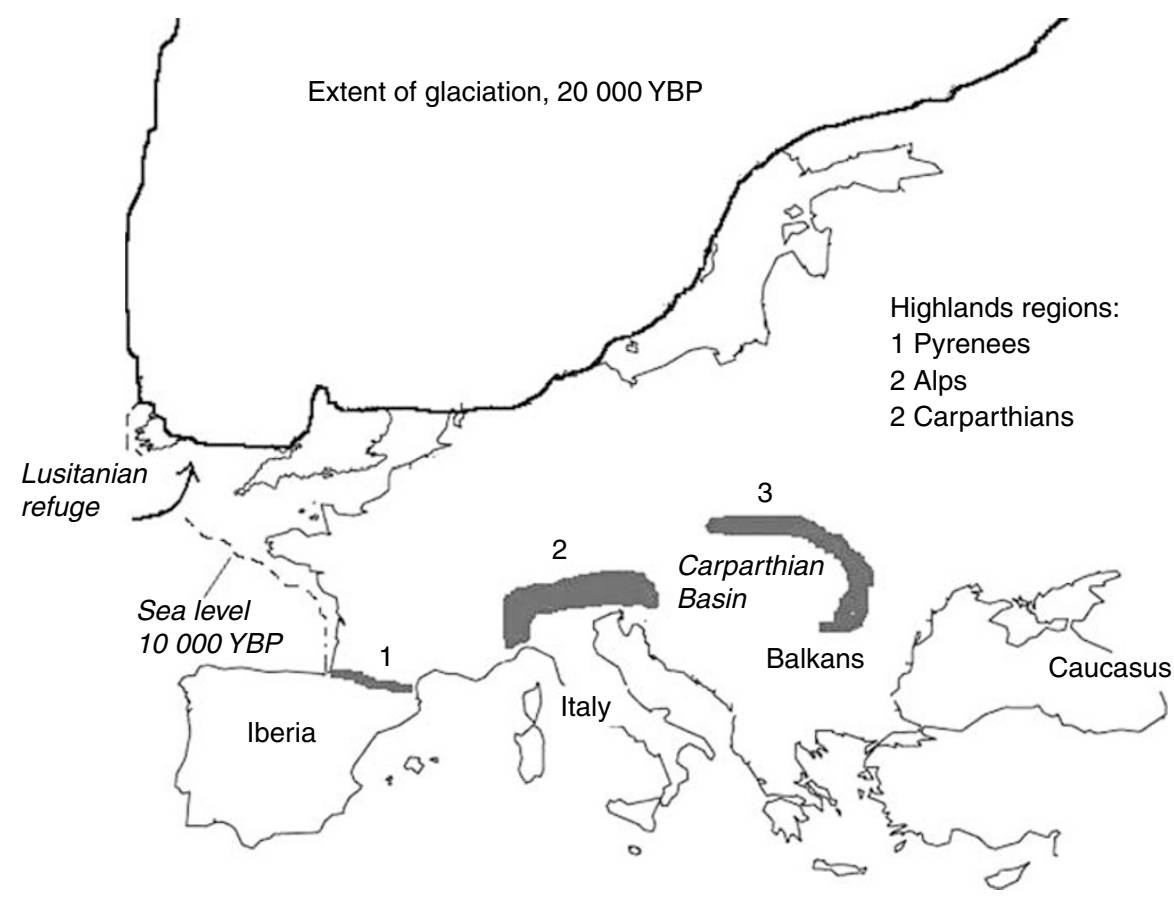

Figure 4 European phylogeography; historical and physical features. 
Arctic Circle. MtDNA (cytb) studies of $R$. arvalis identified three main lineages (Babik et al., 2004), all of which occur at its southerly range limit in the Carparthian basin. Only one of these lineages, however, occurs across the large expanse of the moor frog's range in northern Europe. Northerly (postglacial) colonization probably occurred from refugia harbouring this lineage in the Carparthian basin and in southern Russia. Cytb analysis of $R$. temporaria detected two main lineages, in eastern and western Europe, respectively, that diverged in the mid-Pleistocene about 700000 YBP (Palo et al., 2004). Data from eight microsatellite loci demonstrated a high level of population differentiation across the range of $R$. temporaria, including previously glaciated regions that can only have been occupied within the last 10000 years. Genetic diversity declined as a function of latitude, however, as expected if colonization events reflect serial bottlenecks generated by small numbers of founders (Ibrahim et al., 1996). Relative diversity estimates implied the possibility of multiple cryptic refugia in western Europe, but possibly only one in the colder, more arid eastern region. In common with numerous other species (Taberlet et al., 1998), it seems that Scandinavia was colonized by common frogs both from the south (via Denmark) and the north (via Finland), generating a region of secondary contact in central Sweden. Arguably more surprising, however, is the inference of cryptic northern refugia for the natterjack toad $B$. calamita. This relatively thermophilic species requires open, sunny habitats and warm ephemeral ponds for reproduction. However, mtDNA (control region) analysis demonstrated that the entire north and central European range of this species consists of a single clade virtually absent from Iberia, the species' only long-term southerly refuge (Rowe et al., 2006). This clade diverged from the other four, found in south-west France and Iberia, during the mid-Pleistocene, and thus toads must have survived the last glacial maximum somewhere in western Europe, perhaps in coastal regions where the climate was partly ameliorated. Fine-scale analysis with eight microsatellite loci also implicated relatively recent, short-lived northerly refugia during the Younger Dryas cooling, including one that probably provided colonists for south-west Ireland (as one of the 'Lusitanian' biota) and north-west England.

Amphibian studies have also demonstrated substantial biogeographical structure within the long-term peninsula refugia. The Apennine yellow-bellied toad Bombina pachypus is confined to Italy. $C y t b$ and allozyme analysis showed that populations in the far south of the country were the most diverse, but that this was not simply attributable to long-term refuge stability (Canestrelli et al., 2006). Local barriers to dispersal (low-lying plains) in the south also generated allopatric differentiation followed by secondary intermixing. Low diversity further north in the Apennine Mountains is probably a result of both historical factors (cold periods during the Pleistocene) and recent habitat destruction by humans that has reduced population sizes and gene flow between them. Two other Bombina species (bombina and variegata) meet in a long-studied allopatric hybrid zone in eastern Europe (Szymora and Barton, 1986). MtDNA (cox1 and nad4 sequence) analysis, including NCA and mismatch distribution analysis, indicated the likely postglacial origins of both species in Hungary and

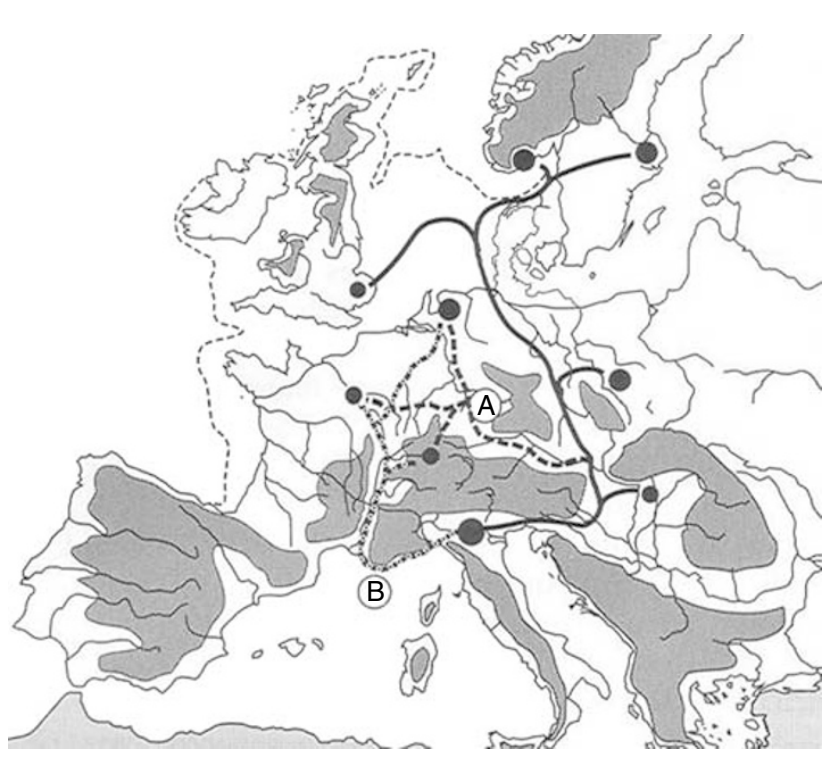

Figure 5 Postulated postglacial colonization of northern and central Europe by Rana lessonae (after Zeisset and Beebee, 2001). (A, B) Alternative possible routes for colonization of central/western Europe from Italian or Carparthian Basin refugia. Solid circles: sampling sites for genetic data.

suggest that a northward colonization of $B$. bombina may have led to increased isolation of western $B$. variegata populations (Voros et al., 2006).

Phylogeographical approaches have also proved useful in Europe to investigate the origins of range-margin populations, which may have arisen naturally or as a result of human activities. Microsatellite and random amplified polymorphic DNA analyses strongly inferred that some populations of the pool frog $R$. lessonae in eastern England were native to the country, rather than a recent introduction as previously thought, and are part of a distinct clade only otherwise found in Scandinavia (Zeisset and Beebee, 2001; Snell et al., 2005). A rather unexpected northerly postglacial colonization route westwards from Scandinavia (Figure 5) may, it turns out, have been followed by other organisms as well (Bunje, 2005; Piertney et al., 2005). In contrast, Cytb studies of tree frog (Hyla species) in Switzerland revealed two distinct clades, corresponding to H. arborea (native to the northern plateau) and $H$. intermedia (native only south of the Alps). However, individuals of the $H$. intermedia clade were also found in one region north of the Alps, implying a recent translocation by humans (Dubey et al., 2006).

Evidently patterns of historical events in Europe, as in North America, strongly feature postglacial colonizations following retreat of the glaciers starting more than 16000 YBP. Major refugia in Europe were more clearly defined, as Mediterranean peninsula, than was often the case in North America. However, mountain ranges were more effective barriers to colonization in Europe because they predominantly run east-west, partly isolating the southerly refugia, rather than north-south as in the Americas. Even so, in both continents, it has also become clear that assuming survival occurred only in these southerly warm regions during the last glacial maximum is naive. The genetic data strongly imply that many species also persisted in refugia substantially further 
north than previously believed. A novel application of phylogeography to identify the likely origins of rangemargin amphibian populations has proved useful in conservation biology, differentiating as it does between the diametrically opposed policies of conservation priority (where native status is implied) and potential eradication (where alien introduction is implied, Beebee et al., 2005).

\section{Tropical and south temperate zones: South America and island biotas}

With the exception of parts of Patagonia, the more southerly continents mostly escaped direct effects of ice cover during the Pleistocene. However, there were extensive indirect effects largely manifest as cycles of varying temperature, rainfall and aridity, which in turn caused expansions and contractions of rainforest and grassland or desert conditions. Aridity cycles also occurred earlier, as well as marine incursions, in the Tertiary. Very little has been reported on the phylogeography of mainland African anurans, excepting some study on Xenopus (Evans et al., 2004), but the situation in South America (Figure 6) has been the subject of many studies.

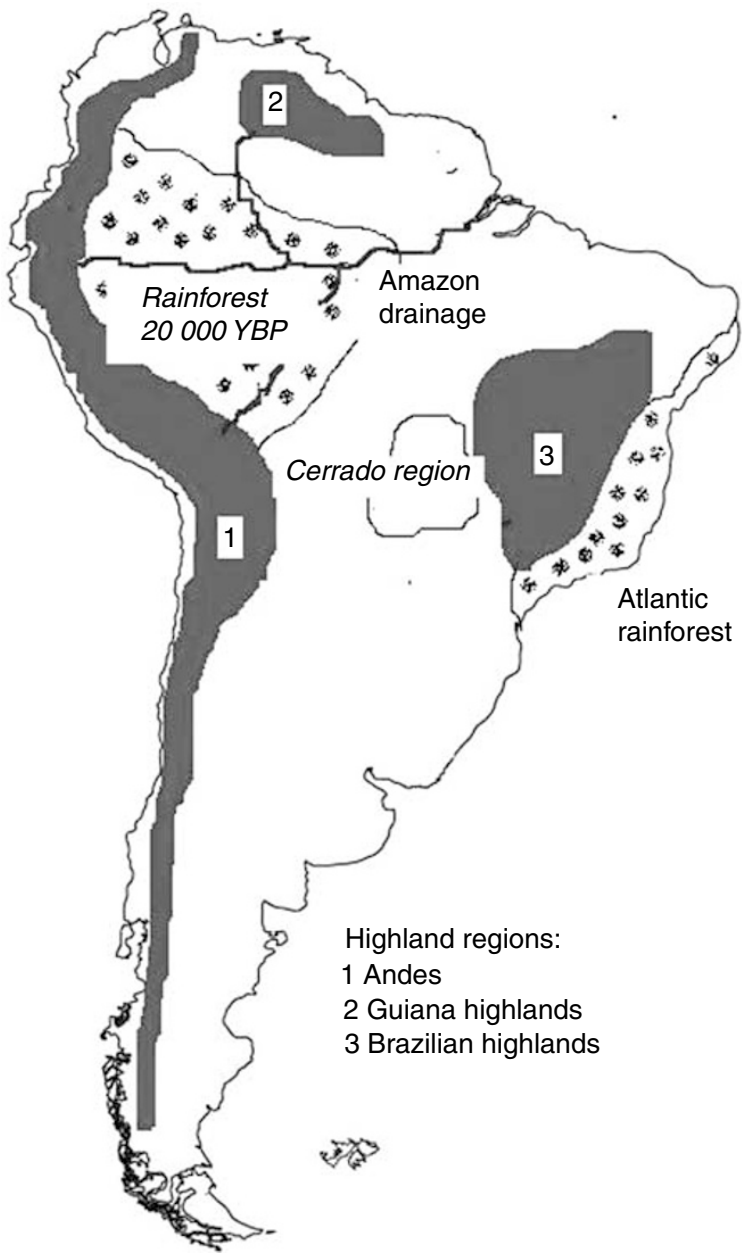

Figure 6 South American phylogeography; historical and physical features.
Biogeographical patterns in tropical South America are thought to have arisen consequent on one or more of the following factors (Figure 7):

(a) Changing distributions of land and sea or in the landscape due to tectonic movements or sea level fluctuations (the Palaeogeography hypothesis).

(b) Barrier effects of Amazonian rivers (the River hypothesis).

(c) The existence of isolated refugia during dry climatic periods of the Tertiary and Quaternary (Refuge hypothesis).

(d) A combination of barrier effects of broad rivers and vegetational changes during periods of aridity (the Climatic/River refuge hypothesis).

(e) Competitive interactions between species during the cool periods of the Pleistocene (the disturbancevicariance (DV) hypothesis).

As tropical regions have not experienced such dramatic climatic fluctuations as those at high latitudes, genetic variation in tropical species is generally expected to be higher than in temperate zones where population bottlenecking has been more frequent and intense. High intraspecific mtDNA variation certainly seems to be a common feature of tropical anurans, at least in South America. $C y t b$ variation in the dart-poison frog Epipedobates femoralis, an Amazonian forest species, was used to test two competing hypotheses about barriers to gene flow in the region (Lougheed et al., 1999). Differentiation was not strong across the Rio Juruá, thus discounting this large river as a substantial barrier to gene flow, but correlated well with the site of an ancient (now degraded) ridge that existed some 5-15 million YBP. The very low individual mobility of this frog has apparently led to the retention of a genetic barrier signature in a region where no obvious barrier to movement persists today and seems to support the palaeogeography hypothesis. Subsequently, however, a broad-ranging study of poison frogs in the genus Dendrobates addressed both the palaeogeographical (including ridge) and river barrier hypotheses as well as three other scenarios (climatic refuge, river refuge and temperature-based DV) that might explain the history of Amazonian biota distributions (Noonan and Wray, 2006). A total of $1400 \mathrm{bp}$ of mtDNA (cytb, CO1, 12S and 16S rRNA genes) were sequenced and used initially to reevaluate phylogenetic relationships between 20 taxa within the Dendrobates genus. The palaeogeographic hypothesis probably explains both an early split between two groups as a result of the Neogene uplift of the northern Andes and further differentiation based on extensive marine incursion rather than the effects of ancient ridges. For the one species it was possible to test (D. ventrimaculatus), there was evidence of riverine barriers in deepwater regions near tributary confluences, but not around headwaters. Although species distributions matched previously postulated refugia, there was virtually always only one species per refuge, suggesting that there have not been intermediate periods of isolation and connectivity promoting widespread gene flow between refuge areas as their likely origins in the Miocene. There was no clear support for river-associated refugia, and most of the differentiation among Dendrobates species seems to have arisen before the Pleistocene 
a

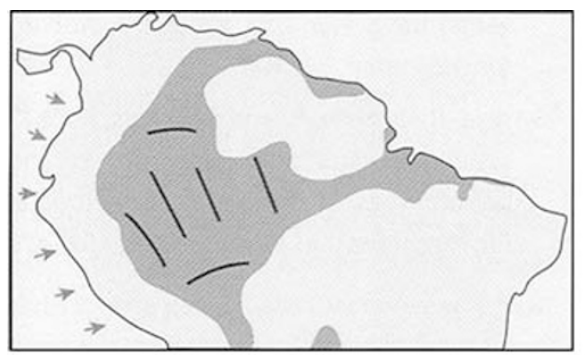

C

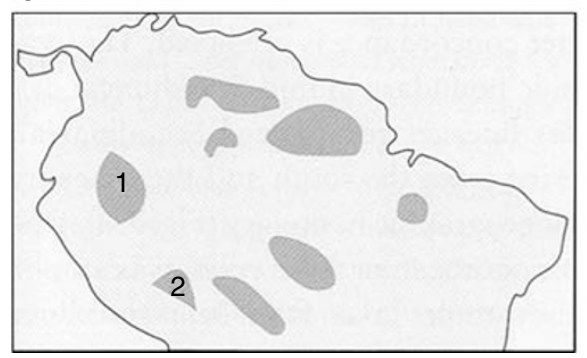

b

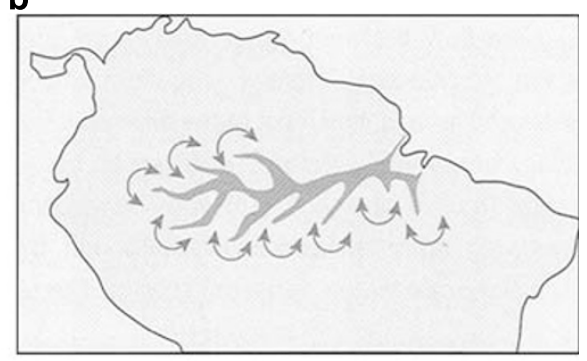

d

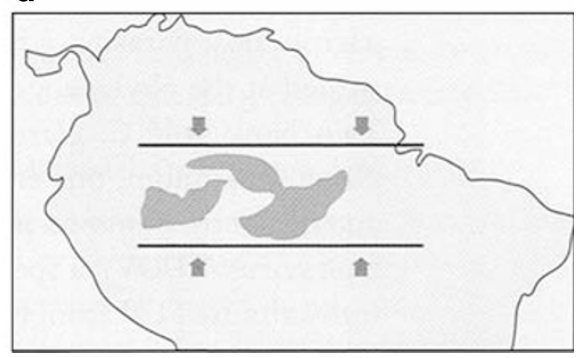

Figure 7 Phylogeographic history hypotheses for northern South America. (a) Palaeogeography hypothesis: shaded area indicates likely Miocene marine incursion, dark lines are ridges and arrows indicate crustal movements. (b) Riverine barrier hypothesis, with arrows indicating routes of possible gene flow. (c) Refuge hypothesis, with shaded areas = refugia. 1 (Napo) and 2 (Inambari) are proposed major refugia. (d) River refuge hypothesis, with horizontal bars indicating latitudinal constriction of humid forest and shaded areas representing corridors with forest cover. After Noonan and Wray, 2006.

(thus it is not consistent with Pleistocene, temperaturebased DV), although this hypothesis might explain finescale events for some species. Overall, a complex picture suggests that several different non-exclusive hypotheses have probably generated current distribution patterns of Dendrobates species.

Studies with harlequin toads (Atelopus species) and the dyeing poison frog Dedrobates tinctorius, a species endemic to the Guiana Shield, have further tested the competing hypotheses about the origins of tropical frog distributions in South America (Noonan and Gaucher, 2005, 2006). The Guiana shield is a biodiversity hotspot for amphibians, with high levels (almost 50\%) of endemism, although harlequin toads are among the most serious casualties of global amphibian declines (Pounds et al., 2006). The refuge hypothesis proposes that climatic oscillations during the Tertiary generated forest islands in northern South America with randomly composed biotic communities (Brown, 1987), whereas the DV hypothesis postulates a more recent (Pleistocene) series of environmental fluctuations facilitating, during cool periods, the eastward spread of species previously confined to the Andes. Both of these studies supported the DV rather than the refuge scenario. MtDNA analyses indicated a Miocene origin for the Atelopus group, but with differentiation of lineages within the Guianian region during the Quaternary. These eastern mountain frogs represent cool-adapted invaders originally from the Andes, and their genetics and distribution are inconsistent with the refuge hypothesis prediction of diverse genetic groups in each of multiple biodiversity reservoirs. Further study of $D$. tinctorius indicated that two lineages, originally associated with the western and eastern upland regions of the Shield, respectively, have recently expanded and now share secondary contacts over a broad central distribution. These contacts date to the Pleistocene and were probably multiple. Taken together, the data strongly support temperature fluctuations during the Quaternary, rather than aridity in the Tertiary, as the main driver of current genetic distributions within these frog species.

Perhaps unsurprisingly, explaining the biogeography of such a vast area of tropical rainforest and associated uplands is particularly problematic. Many of the critical events in this relatively stable region probably predate the Pleistocene. Nevertheless, it looks as if the distribution of the more thermophilic (lowland forest) species may be best explained by the palaeogeographic hypothesis, in combination with riverine barriers where rivers are wide. Conversely, distributions of upland species such as Atelopus may be best explained by more recent events during the Quaternary (the DV hypothesis).

Islands provide special opportunities for investigating past colonization processes. Amphibians have low salt tolerances and none can survive prolonged immersion in sea water (Beebee, 1996) except where salinity is atypically low, such as in the Baltic. Many oceanic islands are therefore devoid of amphibians, but some are not. Madagascar is a particularly interesting case. It separated from mainland Africa some 130 million YBP, was occupied by humans as recently as $2000 \mathrm{YBP}$, and has over 200 species of anurans more than $99 \%$ of which are endemic (Vences et al., 2004). However, the Mascarene ridged frog Ptychadena mascarensis is one of only two species found extensively in mainland Africa as well as in Madagascar. MtDNA 16S rRNA sequence analysis of 78 specimens collected across the entire biogeographical range generated a fascinating inference (Vences et al., 2004). Madagascar frogs had a range of haplotypes found nowhere on the mainland, and which included two very 


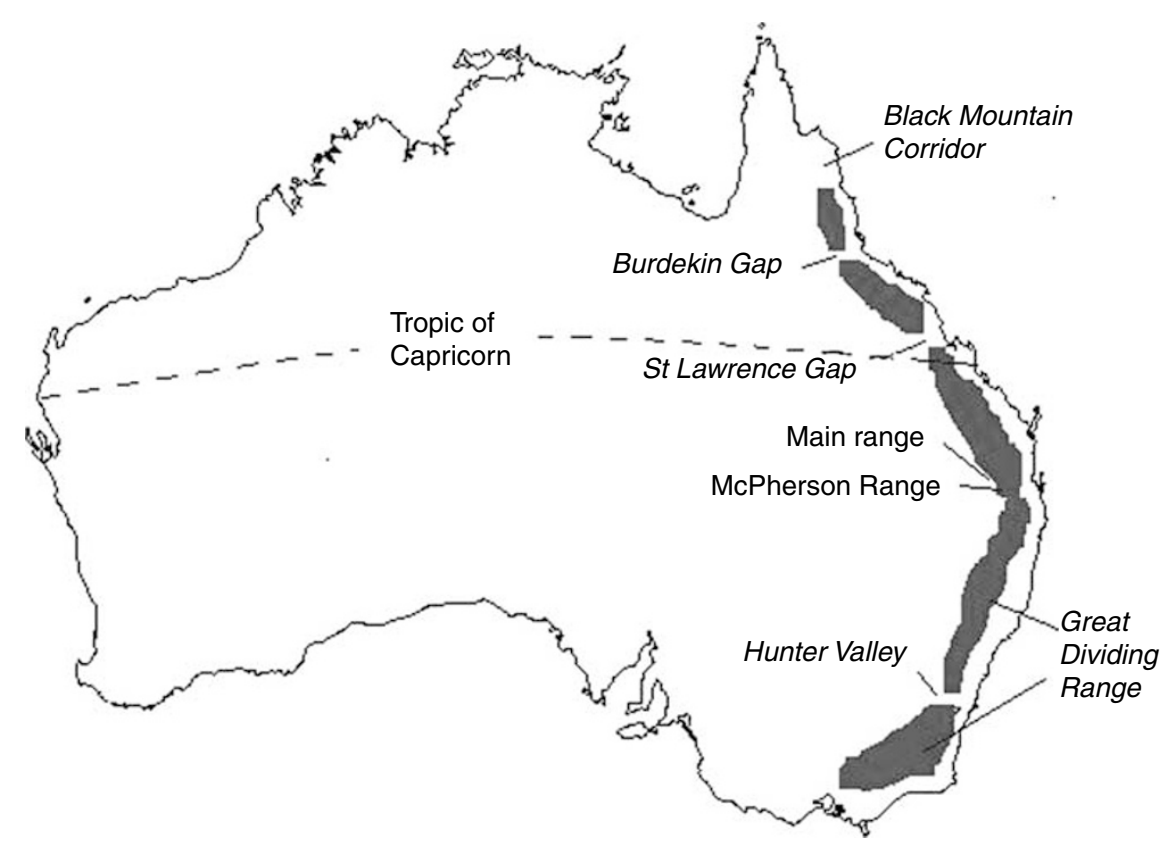

Figure 8 Australian phylogeography; historical and physical and features.

divergent lineages within the island. These results indicate that Madagascar was colonized naturally by transoceanic dispersal long before humans arrived, but much more recently than its separation from Africa. Others have investigated some of the endemic Madagascan anurans; particularly poison frogs in the genus Mantella. Rain forests on Madagascar are of course much less extensive than those in South America, facilitating biogeographical study at a finer level of scale. The endangered $M$. bernhardi occurs in two separate regions in south-east Madagascar. $C y t b$ sequence comparisons of individuals from across the entire range confirmed the genetic separation (reciprocal monophyly) of the two groups and provided evidence of barriers to gene flow (probably rivers) predating the recent habitat destruction mediated by humans (Vieites et al., 2006).

Australia is both an island and a continent, with a very high level of endemism, and supports more than 200 species of anurans (Beebee, 1996). Most of these inhabit the wettest, eastern side of Australia in a north-south temperature cline from tropical to temperate regions (Figure 8). The arid nature of most of the continent has restricted rainforest patches to areas in this eastern zone, a situation that (as in Madagascar) facilitates phylogeographic studies by comparison with the much more extensive forest habitats in South America and Africa. Australia experienced very little glaciation (limited to small areas of Tasmania and the Snowy Mountains) during the Pleistocene, but the cold periods were associated with increased aridity and reductions in areas of rainforest, possibly to small pockets, within the mountain regions. Topography, by contrast, has been relatively constant since the uplift of the dividing range mountains about 65 MYA. Various gaps in these mountains, running broadly east-west (Figure 8), may have constituted specific barriers to migration between montane rain forests especially during arid periods.

A major phylogeographic question is whether Australian frogs invaded southwards from New Guinea (then attached by a land bridge) during the Pleistocene or whether current population structure has a more ancient history within Australia. Studies of $c y t b$ variation in rainforest species in northern Queensland, including three species of tree frogs (Litoria genimaculata, L. nannotis and $L$. rheocola), revealed a strikingly concordant genetic break across the Black Mountain Corridor north of Cairns (Schneider et al., 1998). This major split arose in the Tertiary and was in a forest disjunction area predicted by palaeoclimatic modelling, but finer scale analysis also inferred substantial effects of Pleistocene climatic variations both north and south of the Black Mountain Corridor. There is evidence of population fragmentation in multiple refugia, followed by expansion during the Holocene as rainforest recovered. Evidently, relatively recent historical events have played a substantial part in determining the current distributions of species in these tropical rainforests. Open forest frogs, by contrast, thrive in drier habitats, and some species have distributions that span both tropical and subtropical/temperate regions. These frogs are predicted to expand their populations under dry climatic conditions that cause wet tropical species to contract. One such species, the eastern sedge frog L. fallax, demonstrated a sharp mtDNA differentiation into two old (Pliocene) lineages, this time across the McPherson Range (another widely recognized biogeographical boundary) near the Queensland-New South Wales border (James and Moritz, 2000). The dry savanna of the Burdekin Gap in Queensland was also a phylogeographic boundary within the northern clade of L. fallax, more so than for rain forest species, a surprising result considering the ecological associations of these amphibians. The effects of the Burdekin Gap, but not the McPherson Range, were also found with two other open forest frogs, Limnodynastes tasmaniensis and L. peronii (Schauble and Moritz, 2001). Taken together, these results strongly imply a major role of vicariance events in the Pliocene, rather than recent colonization from New Guinea, as 
determinants of east Australian frog distributions. Further south, the golden bell frog Litoria aurea of south-eastern Australia showed no significant phylogenetic breaks across its entire distribution, indicating (for example) that the Hunter Valley has not served as a barrier to dispersal in this species (Burns et al., 2007). The genetic signatures from both mtDNA and microsatellite analyses indicated that this frog probably experienced a substantial population expansion starting during the late Pleistocene, some 200000 YBP.

Most of the major phylogenetic splits now evident in east Australian frogs, including some speciation events, date back to the Neogene while finer-scale differentiation has its origins in the climatic oscillations of the Pleistocene. Evidently, the endemic anurans of Australia have a long history on that continent.

\section{Conclusions and future developments}

Phylogeographical analysis has provided unprecedented insights into the role of history in the generation of extant biological communities, an achievement exemplified by studies on anuran amphibians from all the continents in the world. Understanding the distribution of genetic diversity in space has provided indications of how speciation events were initiated, and permits tests of hypotheses concerning range borders. Thus, genetic diversity at neutral loci such as microsatellites often declines towards range edges as a consequence of historical colonization processes, as predicted from theory (Ibrahim et al., 1996). Phylogeography has also provided specific information about factors influencing gene flow. Mountain regions can act as barriers to thermophilic species restricted to low elevations, but in other circumstances, they can act as refugia, as during periods of aridity in lowland areas. Major rivers, but not usually minor tributaries or headwaters, can act as partial barriers to gene flow. Many of these features have been demonstrated with other taxa, including large mammals. Bonobos Pan paniscus, experience a barrier effect from rivers in the Congo basin (Eriksson et al., 2004), and thinhorn sheep Ovis dalli experience mountain barrier effects (Worley et al., 2004). Current distributions of genetic diversity sometimes have a long history, predating the major climatic disruptions of the Pleistocene glaciations, although these too have had major effects far beyond regions directly affected by ice. Genetic data are often sufficient both to identify past refugia used during periods of climatic deterioration and to infer subsequent colonization routes that generated current distribution patterns, sometimes at a very fine level of scale. A combination of mtDNA and microsatellite data is particularly powerful in this regard. We have also learnt that refugia were more complex in time and space than previously assumed. In Europe and North America, for example, it has become clear that even during the last glacial maximum around 20000 YBP, many organisms, including amphibians, must have survived further north than previously realized (Stewart and Lister, 2001; Rowe et al., 2004, 2006).

Despite these considerable achievements, important challenges remain. Discord between results from mtDNA and allele frequency analyses are not uncommon, and explanations for such discrepancies can be problematic. There are numerous cases of allozymes failing to reveal population genetic structures that show up with mtDNA (Avise, 2000). In the case of Korean pond frogs $R$. nigrmaculata, allozyme-based phylogenies failed to separate Japanese from Korean populations, whereas this distinction was robustly made with mtDNA (Kim et al., 1999). Differences in mutation rates, or perhaps balancing selection on some allozyme loci that are therefore not truly neutral, may account for these cases. However, such explanations are less convincing when mtDNA and microsatellite data deliver different inferences, as occurred with R. cascadae in North America (Monsen and Blouin, 2003). Male-biased gene flow and limits to the potential allelic diversity of microsatellite loci were unlikely explanations in this case for the much higher level of differentiation of frogs between the Olympic and Washington Cascades mountains inferred from the mtDNA compared with the microsatellite data. According to the authors, a more likely reason for the differences may stem from incomplete sampling (and thus underestimates of mtDNA diversity) coupled with past population bottlenecks that would probably have reduced mtDNA diversity (due to its fourfold, smaller, effective population size) much more than microsatellite diversity. It will be important in future studies to increase comparative phylogeographical analyses with multiple marker types, to address such questions of apparent incompatibility in a more comprehensive manner.

These and other issues have led to the development of methods that should permit a more rigorous, statistical appraisal of phylogeographic hypotheses (Knowles and Maddison, 2002; Knowles, 2004). Until recently, most conclusions have been based on post hoc interpretations of gene trees and/or the results of NCA and mismatch distribution analysis. Neither of these approaches permits full statistical comparisons of different explanatory models, which ideally should be derived a priori and used to inform sampling strategies. Many factors potentially complicate simplistic interpretation of gene trees, including stochastically derived differences due to lineage sorting between gene and population histories. Choosing appropriate models to test will often be a difficult compromise between sufficient simplicity as to be workable and sufficient complexity as to be realistic. In particular, it will be increasingly important to use multiple loci and include model parameters of migration rates, admixture and effective population sizes. Fortunately, ever more sophisticated analytical methods are becoming available for this task using coalescent-based, Bayesian and likelihood approaches (Knowles, 2004). Recent studies with Ascaphus species in North America, combining genetic and ecological models, is a good example of how phylogeographic inferences can be tested and refined (Carstens and Richards, 2007).

Amphibian phylogeography has been widely studied over the past decade. Future studies should reveal whether the anuran patterns on the various continents are typical of other primarily terrestrial, low-mobility taxa such as most reptiles, mammals and many flightless insects. Indeed, it will be intriguing to discover whether there are relatively small number of global phylogeographic patterns that account for the distribution of most of the world's biota. Eventually, this should provide an insight into one of ecology's outstanding questions, notably the relative importance of historical processes and species-specific interactions in structuring biological 
communities and the genetic diversity within them. Moreover, the expected rapid increase in full genomic sequence data should permit the testing of previously inaccessible hypotheses in a phylogeographic context. Especially exciting is the prospect of detecting signatures of selection at the DNA sequence level, and associating these with historical patterns of migration and population differentiation.

\section{References}

Austin JD, Lougheed SC, Boag PT (2004). Discordant temporal and geographic patterns in maternal lineages of east North American frogs, Rana catesbeiana (Ranidae) and Pseudacris crucifer (Hylidae). Mol Phylogenet Evol 32: 799-816.

Austin JD, Lougheed SC, Neidrauer L, Chek AA, Boag PT (2002). Cryptic lineages in a small frog: the postglacial history of the spring-peeper, Pseudacris crucifer (Anura: Hylidae). Mol Phylogenet Evol 25: 316-329.

Avise JC (2000). Phylogeography. Harvard University Press: Cambridge, Massachusetts.

Avise JC, Arnold J, Ball RM, Bermingham E, Lamb T, Neigell CA et al. (1987). Intraspecific phylogeography: the mitochondrial DNA bridge between population genetics and systematics. Ann Rev Ecol Syst 18: 489-522.

Babik W, Branicki W, Sandera M, Litvinchuk S, Borkin LJ, Irwin JT et al. (2004). Mitochondrial phylogeography of the moor frog, Rana arvalis. Mol Ecol 13: 1469-1480.

Beebee TJC (1996). Ecology and Conservation of Amphibians. Chapman \& Hall: London.

Beebee TJC, Buckley J, Evans I, Foster JP, Gent AH, Gleed-Owen CP et al. (2005). Neglected native or undesirable alien? Resolution of a conservation dilemma concerning the pool frog Rana lessonae. Biodivers Conserv 14: 1607-1626.

Bos DH, Sites JW (2001). Phylogeography and conservation genetics of the Columbia spotted frog (Rana luteiventris: Amphibia, Ranidae). Mol Ecol 10: 1499-1513.

Brown KS (1987). Conclusions, synthesis, and alternative hypotheses. In: Whitmore TC, Brown KS (ed). Biogeography and Quaternary History of Tropical America. Oxford University Press: Oxford. pp 175-196.

Bunje PM (2005). Pan-European phylogeography of the aquatic snail Theodoxus fluviatilis (Gastropoda: Neritidae). Mol Ecol 14: 4323-4340.

Burns EL, Eldridge MDB, Crayn DM, Houlden BA (2007). Low phylogeographic structure in a wide spread endangered Australian frog Litoria aurea (Anura: Hylidae). Conserv Genet 8: $17-32$.

Canestrelli D, Cimmaruta R, Costantini V, Nascetti G (2006). Genetic diversity and phylogeography of the Appenine yellow-bellied toad Bombina pachypus, with implications for conservation. Mol Ecol 15: 3741-3754.

Carstens BC, Richards CL (2007). Integrating coalescent and ecological niche modeling in comparative phylogeography. Evolution 61: 1439-1454.

Dubey S, Ursenbacher S, Fumagalli L (2006). Origin of tree frog (Hyla spp.) populations in western Switzerland. Rev Suisse Zool 113: 879-887.

Duellman WE, Trueb L (1986). Biology of Amphibians. McGrawHill Publishing Co.: New York.

Eggert C, Cogalniceanu D, Veith M, Dzukic G, Taberlet P (2006). The declining spadefoot toad, Pelobates fuscus (Pelobatidae): paleo and recent environmental changes as a major influence on current population structure and status. Conserv Genet 7: 185-195.

Eriksson J, Hohmann G, Boesch C, Vigilant L (2004). Rivers influence the population genetic structure of bonobos (Pan paniscus). Mol Ecol 13: 3425-3435.

Evans BJ, Kelley DB, Tinsley RC, Melnick DJ, Cannatella DC (2004). A mitochondrial DNA phylogeny of African clawed frogs: phylogeography and implications for polyploid evolution. Mol Phylogenet Evol 33: 197-213.

Hewitt G (2000). The genetic legacy of the quaternary ice ages. Nature 405: 907-913.

Hewitt GM (1999). Post-glacial re-colonization of European biota. Biol J Linn Soc 68: 87-112.

Hewitt GM (2001). Speciation, hybrid zones and phylogeography-or seeing genes in space and time. Mol Ecol 10: 537-549.

Hoffman EA, Blouin MS (2004). Evolutionary history of the northern leopard frog: reconstruction of phylogeny, phylogeography, and historical changes in population demography from mitochondrial DNA. Evolution 58: 145-159.

Ibrahim KM, Nichols RA, Hewitt GM (1996). Spatial patterns of genetic variation generated by different forms of dispersal during range expansion. Heredity 77: 282-291.

Jaeger JR, Riddle BR, Bradford DF (2005). Cryptic Neogene vicariance and quaternary dispersal of the red-spotted toad (Bufo punctatus): insights on the evolution of North American warm desert biotas. Mol Ecol 14: 3033-3048.

James CH, Moritz C (2000). Intraspecific phylogeography in the sedge frog Litoria fallax (Hylidae) indicates pre-Pleistocene vicariance of an open forest species from eastern Australia. Mol Ecol 9: 349-358.

Kim J-B, Lee H-Y, Yang S-Y (1999). Genetic variation of the mitochondrial cytochrome $b$ gene sequence in a Korean pond frog, Rana nigromaculata, with a report of the discordance in the genetic divergence of mtDNA and nuclear DNA. Korean J Genet 21: 127-134.

Knowles LL (2004). The burgeoning field of statistical phylogeography. J Evol Biol 17: 1-10.

Knowles LL, Maddison WP (2002). Statistical phylogeography. Mol Ecol 11: 2623-2635.

Lougheed SC, Gascon C, Jones DA, Bogart JP, Boag PT (1999). Ridges and rivers: a test of competing hypotheses of Amazonian diversification using a dart-poison frog (Epipedobates femoralis). Proc Roy Soc Lond B 266: 1829-1835.

Monsen KJ, Blouin MS (2003). Genetic structure in a montane ranid frog: restricted gene flow and nuclear-mitochondrial discordance. Mol Ecol 12: 3275-3286.

Moriarty EC, Cannatella DC (2004). Phylogenetic relationships of the North American chorus frogs (Pseudacris: Hylidae). Mol Phylogenet Evol 30: 409-420.

Nielson M, Lohman K, Daugherty CH, Allendorf FW, Knudson KL, Sullivan J et al. (2006). Allozyme and mitochondrial DNA variation in the tailed frog (Anura: Ascaphus): the influence of geography and gene flow. Herpetologica 62: 235-258.

Nielson M, Lohman K, Sullivan J (2001). Phylogeography of the tailed frog (Ascaphus truei): implications for the biogeography of the Pacific northwest. Evolution 55: 147-160.

Noonan BP, Gaucher P (2005). Phylogeography and demography of Guianan harlequin toads (Atelopus): diversification within a refuge. Mol Ecol 14: 3017-3031.

Noonan BP, Gaucher P (2006). Refugial isolation and secondary contact in the dyeing poison frog Dendrobates tinctorius. Mol Ecol 15: 4425-4435.

Noonan BP, Wray KP (2006). Neotropical diversification: the effects of a complex history on diversity within the poison frog genus Dendrobates. J Biogeog 33: 1007-1020.

Palo JU, Schmeller DS, Laurila A, Primmer CR, Kuzmin SL, Merilä J (2004). High degree of population subdivision in a widespread amphibian. Mol Ecol 13: 2631-2644.

Petit RJ (2008). Perspective-the coup de grâce for the nested clade phylogeographic analysis? Mol Ecol 17: 516-518.

Pielou EC (1991). After the Ice Age: the Return of Life to Glaciated North America. University of Chicago Press: Chicago.

Piertney SB, Stewart WA, Lambin X, Telfer S, Aars J, Dallas JF (2005). Phylogeographic structure and postglacial evolutionary history of water voles (Arvicola terrestris) in the United Kingdom. Mol Ecol 14: 1435-1444.

Pounds JA, Bustamante MR, Coloma LA, Consuegra JA, Fogden MP, Foster PN et al. (2006). Widespread amphibian 
extinctions from epidemic disease driven by global warming. Nature 439: 161-167.

Riddle BR, Hafner DJ (2006). A step-wise approach to integrating phylogeographic and phylogenetic biogeographic perspectives on the history of a core North American warm deserts biota. J Arid Envir 66: 435-461.

Ritland K, Dupuis LA, Bunnell FL, Hung WLY, Carlson JE (2000). Phylogeography of the tailed frog (Ascaphus truei) in British Columbia. Canad J Zool 78: 1749-1758.

Rowe G, Harris DJ, Beebee TJC (2006). Lusitania revisited: a phylogeographic analysis of the natterjack toad Bufo calamita across its entire biogeographical range. Mol Phylogenet Evol 39: 335-346.

Rowe KC, Heske EJ, Brown PW, Paige KN (2004). Surviving the ice: Northern refugia and postglacial colonization. Proc Nat Acad Sci USA 101: 10355-10359.

Schauble CS, Moritz C (2001). Comparative phylogeography of two open forest frogs from eastern Australia. Biol J Linn Soc 74: $157-170$

Schneider CJ, Cunningham M, Moritz C (1998). Comparative phylogeography and the history of endemic vertebrates in the wet tropics rainforests of Australia. Mol Ecol 7: 487-498.

Shaffer HB, Fellers GM, Voss SR, Oliver JC, Pauly GB (2004). Species boundaries, phylogeography and conservation genetics of the red-legged frog (Rana aurora/draytonii) complex. Mol Ecol 13: 2667-2677.

Snell C, Tetteh J, Evans IH (2005). Phylogeography of the pool frog (Rana lessonae Camerano) in Europe: evidence for native status in Great Britain and for an unusual postglacial colonization route. Biol J Linn Soc 85: 41-51.

Soltis DE, Morris AB, McLachlan IS, Manos PS, Soltis PS (2006). Comparative phylogeography of unglaciated eastern North America. Mol Ecol 15: 4261-4293.

Starkey DE, Shaffer HB, Burke RL, Forstner MRJ, Iverson JB, Jansen FJ et al. (2003). Molecular systematics, phylogeogra- phy, and the effects of Pleistocene glaciation in the painted turtle (Chrysemys picta) complex. Evolution 57: 119-128.

Stewart JR, Lister AM (2001). Cryptic northern refugia and the origins of the modern biota. Trends Ecol Evol 16 608-613.

Szymora JM, Barton NH (1986). Genetic analysis of a hybrid zone between fire-bellied toads. Bombina bombina and Bombina variegata, near Cracow in southern Poland. Evolution 40: 1141-1159.

Taberlet P, Fumagalli L, Wust-Saucy AG, Cosson JF (1998). Comparative phylogeography and postglacial colonization routes in Europe. Mol Ecol 7: 453-464.

Vences M, Kosuch J, Rodel M, Lotters S, Channing A, Glaw F et al. (2004). Phylogeography of Ptychadena mascarensis suggests transoceanic dispersal in a widespread AfricanMalagasy frog lineage. J Biogeog 31: 593-601.

Vieites DR, Chiari L, Vences M, Andreone F, Rabemananjara F, Bora $\mathrm{P}$ et al. (2006). Mitochondrial evidence for distinct phylogeographic units in the endangered Malagasy poison frog Mantella bernhardi. Mol Ecol 15: 1617-1625.

Voros I, Alcobendas M, Martinez-Solano I, Garcia-Paris M (2006). Evolution of Bombina bombina and Bombina variegata (Anura: Discoglossidae) in the Carparthian basin: a history of repeated mt-DNA introgression across species. Mol Phylogenet Evol 38: 705-718.

Wallis GP, Arntzen JW (1989). Mitochondrial-DNA variation in the crested newt superspecies-limited cytoplasmic gene flow among species. Evolution 43: 88-104.

Worley K, Strobeck C, Arthur S, Carey J, Schwantje H, Veitch A et al. (2004). Population genetic structure of North American thinhorn sheep (Ovis dalli). Mol Ecol 13: 2545-2556.

Zeisset I, Beebee TJC (2001). Determination of biogeographical range: an application of molecular phylogeography to the European pool frog Rana lessonae. Proc Roy Soc Lond B 268 : 933-938. 